\title{
UM ESTUDO SOBRE AS CONDIÇÕES DE ACESSIBILIDADE EM PRÉ-ESCOLAS
}

\author{
A STUDY ABOUT ACCESSIBILITY CONDITIONS IN PRE-SCHOOLS
}

\author{
Priscila Moreira CORRÊA ${ }^{1}$ \\ Eduardo José MANZINI²
}

\begin{abstract}
RESUMO: A utilização de um instrumento específico é imprescindível para que educadores consigam analisar as condições de acessibilidade física das suas escolas. Objetiva-se, com este trabalho, apresentar os resultados obtidos pela aplicação de um protocolo para avaliação da acessibilidade física, em seis escolas da Educação Infantil de uma cidade do interior paulista. Esse protocolo está constituído por oito rotas utilizadas por alunos, ao se locomoverem e, também, por itens que devem ser avaliados pelo educador, ao transitarem pelas rotas estabelecidas. Os critérios usados para escolha das seis escolas avaliadas foram: 1) ano de construção das escolas; 2) região; e 3) atender a alunos com deficiência física ou visual e/ou deficiência múltipla. A avaliação das escolas possibilitou a análise das condições de acessibilidade, de acordo com: tipos de portão, porta, piso, obstáculos, largura de corredores, desníveis; quadra de esportes; tanque de areia; campo de futebol; bebedouro; e banheiro. Os resultados demonstraram ser possível comparar e distinguir as condições de acessibilidade de cada item do protocolo, para cada uma das seis escolas avaliadas. O protocolo elaborado permite que os profissionais do atendimento educacional especializado cumpram com umas das suas funções, que é de identificar, elaborar e organizar recursos pedagógicos e de acessibilidade.
\end{abstract}

PALAVRAS-CHAVE: Educação especial. Acessibilidade. Instrumentos de avaliação. Adaptação de arquitetura.

\begin{abstract}
The use of a specific instrument is essential for educators to be able to analyze the conditions of physical accessibility of their schools. This paper aims to present results obtained by applying a protocol for assessing the physical accessibility in six pre-schools in a city in the the interior of the state of São Paulo. This protocol is composed by eight routes used by students circulating inside the pre-school and also for items regarding the established routes that should be evaluated by the educators. The criteria used to select the six schools that were evaluated were: 1) year the school was constructed ,2) region, and 3) availability of educational services for students with physical disabilities or visual and / or multiple disabilities. The evaluation of the schools enabled the analysis of accessibility conditions according to: types of entrance gates, doors, floor/pavement, obstacles, width of corridors, pathway inclination, sports court, sand box, soccer field, water fountain, and bathroom. The results showed that it was possible to compare and distinguish conditions of accessibility of each item of the protocol for each of the six assessed schools. The protocol that was developed enables professionals in specialized educational services to perform their tasks, that is, to identify, develop and organize pedagogical and accessibility resources.
\end{abstract}

KEYWORDS: Special Education. Accessibility. Evaluation instruments.

\section{INTRODUÇÃo}

As condições de acessibilidade física das escolas podem estar comprometidas devido à presença de barreiras arquitetônicas, pois muitas construções foram realizadas em épocas não muito recentes, quando o paradigma da inclusão e da filosofia do desenho universal não era concebido pela arquitetura dos edifícios públicos. Além disso, nessa época, não se considerava a presença

\footnotetext{
${ }^{1}$ Doutoranda do Programa de Pós-Graduação da UNESP, Marília. Bolsista CAPES - PROESP. priped@bol.com.br

${ }^{2}$ Livre-docente em Educação, Docente do Programa de Pós-Graduação em Educação e do Depto. de Educação Especial, Unesp, Marília. manzini@marilia.unesp.br
} 
dos alunos com deficiência, nas escolas de ensino comum. Em decorrência, as condições de acessibilidade física dessas escolas podem comprometer o acesso desses alunos, de sorte que ações que visem à adequação e adaptação desses espaços são importantes.

No contexto brasileiro, a acessibilidade física adequada na escola é prevista por diversas leis; todavia, apenas a lei não garante que o profissional da educação consiga planejar ou construir ambientes acessíveis.

A preocupação com a condição da acessibilidade física das escolas de Educação Infantil pode ser demonstrada com as pesquisas realizadas em diferentes Estados do Brasil. Essas pesquisas apresentaram dois tipos de objetivos: 1) obter dados sobre a condição de acessibilidade das escolas da Educação Infantil; 2) oferecer uma proposta de adaptação das escolas, cuja acessibilidade física foi avaliada.

Em relação ao primeiro objetivo, foram encontradas pesquisas realizadas em Natal (CALADO, 2006) e Londrina (ALPINO, 2003). As pesquisas que se referem ao segundo objetivo foram realizadas em Natal (ELALI, 2002), Florianópolis (DISCHINGER et al.; 2004) e São Paulo (CASTRO, 2000; LAUAND, 2000; CARVALHO, 2008).

Nessas pesquisas, foram avaliados diversos aspectos arquitetônicos, que podem interferir na acessibilidade das escolas da Educação Infantil, como: 1) os tipos de portão e portas; 2) os tipos de piso; 3) os tipos de obstáculos, como blocos de concreto, árvores, lixeiras, buracos, tapetes, valetas de água, postes de luz; 4) a largura de corredores; 5) os tipos de desníveis: escadas ou rampas, características do corrimão; 6) a sinalização dos trajetos ou objetos edificados para o aluno com deficiência visual; 7) a identificação dos ambientes, como a utilização do Braille, letreiro em relevo ou pictórica; 8) a quadra de esportes: o seu acesso e lugares reservados para deficiente físico; 9) o bebedouro; 10) o banheiro; 11) o Parque Infantil: o seu acesso e a acessibilidade do seu equipamento; 12) mobiliário escolar, e 13) a iluminação, a temperatura e a cor das escolas.

A maioria dessas pesquisas descritas (CASTRO, 2000; LAUAND, 2000; ELALI, 2002; ALPINO, 2003; DISCHINGER et al., 2004; CALADO, 2006) serviu-se da visita e da observação para a avaliação da condição física das escolas pesquisadas. Também foram empregados outros métodos para essa avaliação, como a obtenção de informações fornecidas pelos profissionais da escola ou pelos alunos (CASTRO, 2000; ALPINO, 2003; DISCHINGER et al., 2004), a Avaliação Pós-Ocupação (CALADO, 2006) e o uso de instrumentos de avaliação (ALPINO, 2003).

Tais investigações demonstraram mais preocupação com a avaliação de alguns locais e elementos das escolas pesquisadas, como o banheiro, os corredores, as rampas, as escadas, os pisos, a sinalização e as portas, que foram examinados pela maioria dessas pesquisas (LAUAND, 2000; ELALI, 2002; ALPINO, 2003; DISCHINGER et al., 2004; CALADO, 2006). 
Cada pesquisa descrita elencou aspectos prioritários para a adequação e a adaptação das escolas. Dessa forma, é importante que os profissionais da educação de cada escola contemplada reflitam sobre esses aspectos, para o início da sua adequação e adaptação.

As adaptações e adequações das escolas devem ser realizadas por meio de instrumentos específicos, que sejam úteis, práticos e objetivem avaliar as condições de acessibilidade desses espaços. Um dos instrumentos que pode ser utilizado para a avaliação da acessibilidade física das escolas da educação infantil se refere ao protocolo elaborado por Corrêa (2010).

A avaliação permite ao profissional da educação ou ao educador fazer um planejamento do ambiente escolar e tornar, do ponto de vista arquitetônico, a escola mais inclusiva, ou seja, identificar quais são as principais barreiras arquitetônicas a interferir na execução das atividades educativas pelos alunos, para adaptá-las ou adequá-las ao uso dos espaços da escola. Mesmo que esse profissional não consiga, de imediato, adaptar as necessidades identificadas na sua escola, por alguma questão - como a orçamentária - ele pode adequar o uso dos espaços da escola, como, por exemplo, remanejar o local da atividade ou evitar que os alunos se locomovam por determinados espaços, que são perigosos e que possuem condições de acessibilidade física ruins.

O protocolo desenvolvido por Corrêa (2010) tem por objetivo avaliar e possibilitar que os educadores façam uma análise das condições de acessibilidade física das escolas de Educação Infantil, de modo a fornecer parâmetros para que os profissionais da educação realizem um planejamento do ambiente escolar mais inclusivo, garantindo um ambiente mais seguro e confortável para todos os alunos.

Nesse sentido, o objetivo do presente trabalho é avaliar a acessibilidade física de seis escolas de Educação Infantil de uma cidade do interior paulista.

\section{Desenvolvimento do estudo}

\subsection{INSTRUMENTO E FORMA DE COLETA}

A avaliação da acessibilidade física das seis escolas de Educação Infantil ocorreu por meio do protocolo desenvolvido por Corrêa (2010), que é composto por duas partes:

Parte A - objetiva avaliar as condições de acessibilidade física de oito rotas definidas;

Parte B - objetiva avaliar as condições de acessibilidade e de segurança dos equipamentos recreativos do parque infantil.

O protocolo permite que os profissionais da educação possam usar as duas partes do instrumento de uma única vez ou utilizar apenas uma parte dele. No presente trabalho, a opção foi apresentar a avaliação realizada com a parte A. 
Na parte A, as condições de acessibilidade física das escolas de Educação Infantil são avaliadas por meio de oito rotas que os alunos usam, ao se locomoverem. Essa forma de avaliação foi igualmente empregada no protocolo de Audi e Manzini (2006). As rotas são os trajetos contínuos, desobstruídos e sinalizados, os quais propiciam o livre caminhar de todas as pessoas, no ambiente escolar (BRASIL, 2004; AUDI; MANZINI, 2006).

As oito rotas estabelecidas são:

- Rota 1 - da entrada da escola para o local de recebimento do aluno;

- Rota 2 - do local de recebimento para o bloco de salas de aula;

- Rota 3 - do bloco de salas de aula para os locais com ambientes fechados (como as salas de vídeo, balé, dormir, salas de jogos, teatro, informática e bibliotecas);

- Rota 4 - do bloco de salas de aula para os locais com ambientes semiabertos (como os quiosques, caramanchões, barracões, tanques de areia, casas de boneca e quadras de esportes cobertas);

- Rota 5 - do bloco de salas de aula para os locais com ambientes ao ar livre (como as hortas, parques, palcos, caramanchões, tanques de areia, campos de futebol, quadras de esportes e piscinas);

- Rota 6 - dos locais com ambientes fechados, semiabertos e ao ar livre para o refeitório;

- Rota 7 - do refeitório para o bebedouro;

- Rota 8 - dos locais com ambientes fechados, semiabertos e ao ar livre para o banheiro.

O profissional da educação ou o educador deve transitar pela rota estabelecida e avaliar os itens que compõem cada uma delas. Esses itens, denominados elementos arquitetônicos, foram elencados em uma ordem hierarquizante - do mais para o menos acessível, ou seja, a primeira alternativa de cada item descrito é a mais acessível, ao passo que a última é a menos acessível. Por exemplo, leve-se em consideração o elemento arquitetônico "portas":

1. As portas possuem:
a. Largura:
a. Maiores que $80 \mathrm{~cm}$ e sem desnível na soleira ( )
b. Maiores que $80 \mathrm{~cm}$ e com desnível na soleira de até $3 \mathrm{~cm} \mathrm{(} \mathrm{)}$
c. Maiores que $80 \mathrm{~cm}$ e com desnível na soleira maior que $3 \mathrm{~cm} \mathrm{(} \mathrm{)}$
d. Menores que $80 \mathrm{~cm}$ e sem desnível na soleira ( )
e. Menores que $80 \mathrm{~cm}$ e com desnível na soleira de até $3 \mathrm{~cm} \mathrm{(} \mathrm{)}$
f. Menores que $80 \mathrm{~cm}$ e com desnível na soleira maior que $3 \mathrm{~cm} \mathrm{(} \mathrm{)}$ 
A alternativa Maiores que $80 \mathrm{~cm}$ e sem desnível na soleira é a mais acessível, enquanto a alternativa Menores que $80 \mathrm{~cm}$ e com desnível na soleira maior que $3 \mathrm{~cm}$ é a menos acessível. Entre os parênteses, o profissional da educação ou o educador deve indicar a quantidade de portas que encontrou com aquelas características.

As rotas envolvem os seguintes elementos arquitetônicos: 1) tipos de portão e portas; 2) tipos de piso; 3) tipos de obstáculos, como blocos de concreto, árvores, lixeiras, buracos, tapetes, valetas de água; 4) largura de corredores ou de caminhos; 5) mudança de desníveis; 6) quadra de esportes; 7) tanque de areia; 8) piscina; 9) campo de futebol; 10) bebedouro; e 11) banheiro.

\subsection{Escolas SELECIONADAS PARA A AVALIAÇÃo DA ACESSIBILIDADE}

Para a aplicação do protocolo, foram selecionadas seis escolas da Educação Infantil, dentre as 28 escolas do Município. Para essa seleção, foram estabelecidos como critérios: 1 ) as gestões municipais em que as escolas foram fundadas; 2) região; e 3) atender a alunos com deficiência física ou visual e/ou deficiência múltipla, uma vez que se esperava que, nessas escolas, devido à presença desses alunos, houvessem sido realizadas reformas para modificações da estrutura arquitetônica do prédio escolar.

As escolas selecionadas estão marcadas com um Xe podem ser visualizadas na Figura 1:

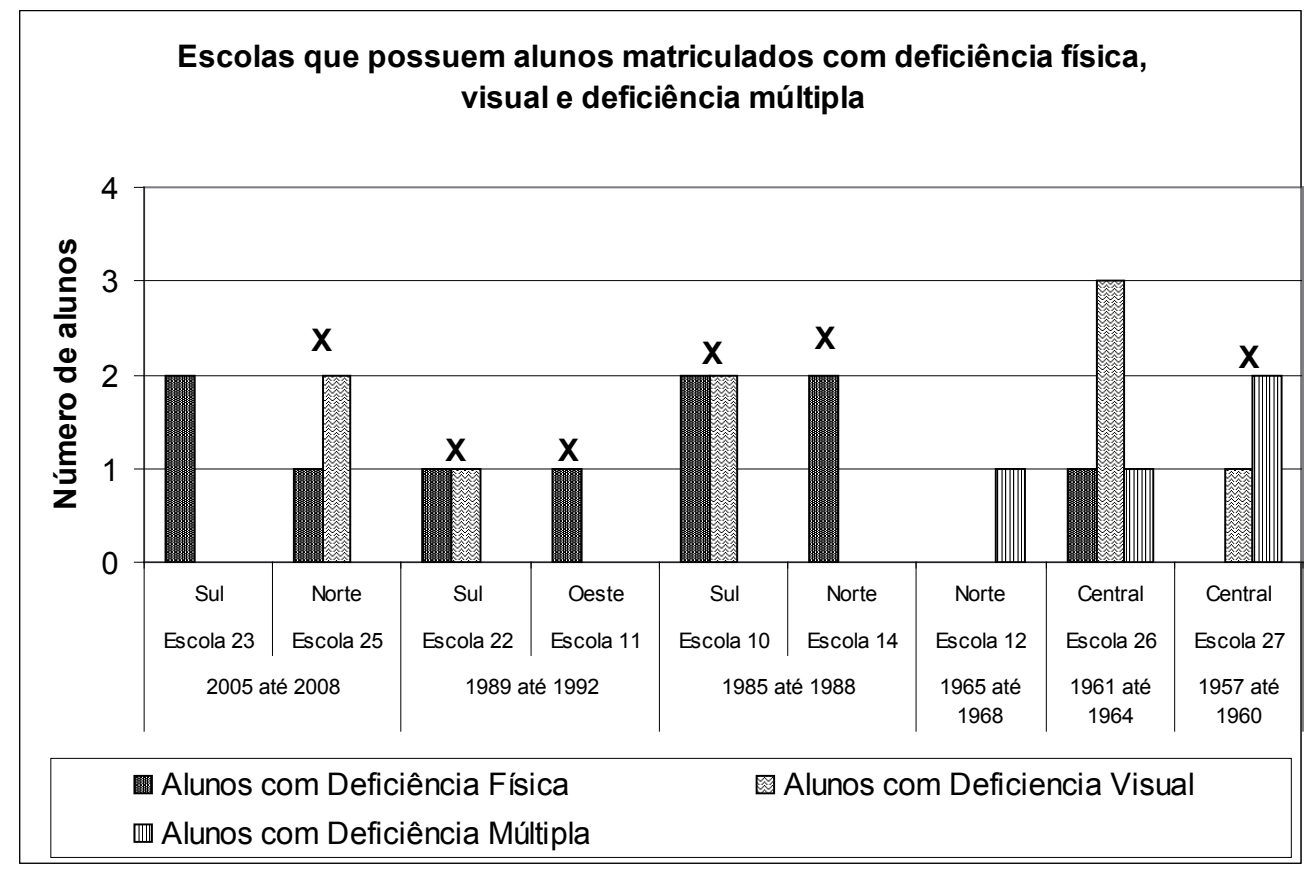

Figura 1 - Escolas selecionadas para a avaliação da Parte A do protocolo 


\subsection{ANÁlise e tRATAMENTO DOS DADOS}

Os dados foram agrupados em uma planilha do Excel para a confecção de gráficos de cada item avaliado.

Os gráficos estão no formato de coluna ou barra e foram subdivididos pelas rotas avaliadas. Em cada rota, foi apresentado o número total de itens encontrados nas seis escolas avaliadas. Em apenas um gráfico, na Figura 15, não foram mantidas essa subdivisões pelas rotas avaliadas, pois foi feita avaliação do elemento encontrado em cada escola avaliada.

Para destacar a acessibilidade obtida em cada item avaliado, foram escolhidas determinadas características para a confecção das alternativas dos gráficos. As alternativas foramelencadas em uma ordem hierarquizante: as primeiras são constituídas pela cor branca, que indicam boa condição de acessibilidade; as alternativas, que possuem duas cores (branco e preto), caracterizam a condição média de acessibilidade; e as últimas alternativas são constituídas pela cor preta, que significam que a condição de acessibilidade é ruim.

\section{RESUltados E Discussão}

Foram avaliadas todas as rotas estabelecidas no protocolo, assim como todos os ambientes fechados, semiabertos e ao ar livre encontrados. Para a descrição dos dados, foi escolhido um ambiente comum entre as seis escolas, nas Rotas 3, 4, 5, 6 e 8. portões":

A Figura 2 apresenta os dados encontrados no item "largura de portas e

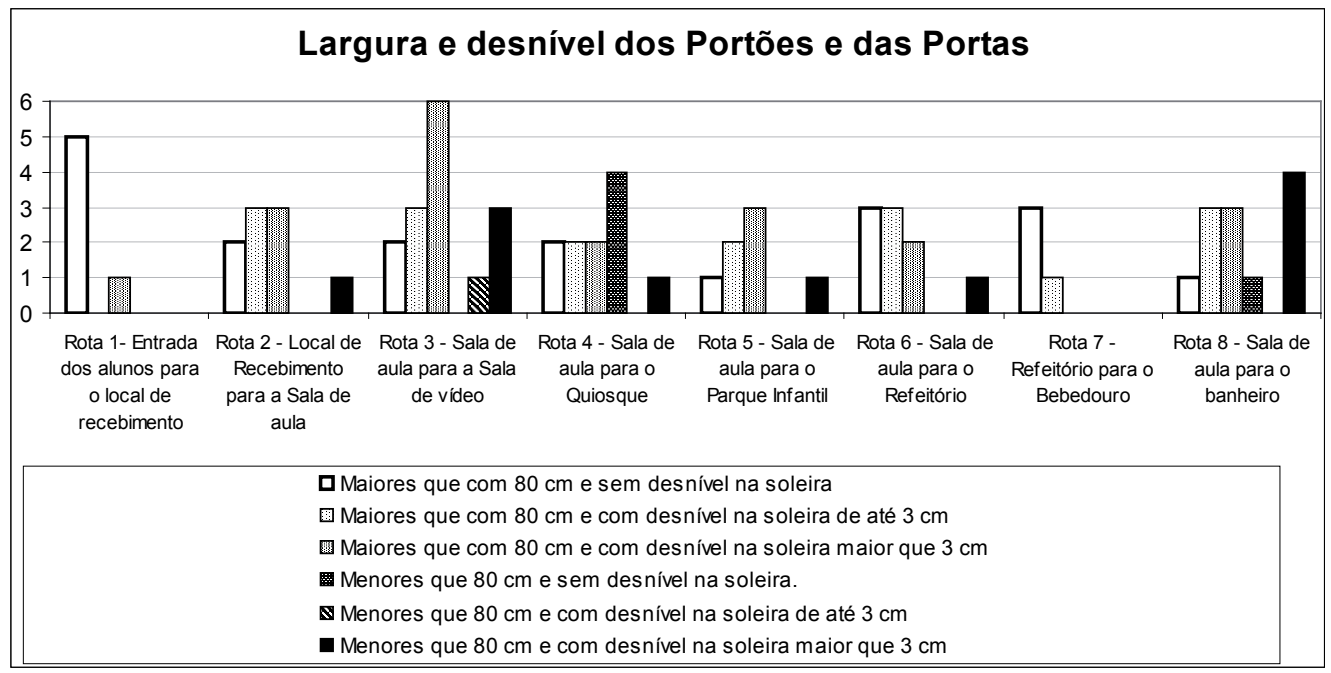

Figura 2 - Avaliação do item "largura de portão e portas" 
Observando-se a Figura 2, constata-se que na, Rota 1, a maioria das escolas apresentou portão de entrada dos alunos considerado como o mais acessível em relação à sua largura e ao seu desnível na soleira (largura maior que $80 \mathrm{~cm}$ e sem desnível na soleira). Na Rota 7, também foram encontradas portas classificadas como as mais acessíveis, na maioria das escolas.

Nas Rotas 2, 3, 4, 5, 6 e 8, as escolas evidenciaram, em sua maioria, portas com largura maior que $80 \mathrm{~cm}$, porém, em algumas, notou-se que o seu desnível estava acima de $3 \mathrm{~cm}$. Além disso, essas rotas apresentaram a alternativa menos acessível referente ao item avaliado, ou seja, portas com largura menor que $80 \mathrm{~cm}$ e com desnível maior que $3 \mathrm{~cm}$.

As portas com larguras ideais, mas com desnível na soleira acima de 3 $\mathrm{cm}$, podem dificultar o acesso dos alunos com deficiência física. Caso esses alunos usem cadeira de rodas, outra pessoa deve auxiliá-los, para que consigam atravessar o desnível da soleira da porta. Já as portas que têm larguras menores que $80 \mathrm{~cm}$ podem impedir o acesso dos alunos com deficiência física, caso estes utilizem cadeiras de rodas ou andadores.

A Figura 3 corresponde ao item "tipo de maçaneta":

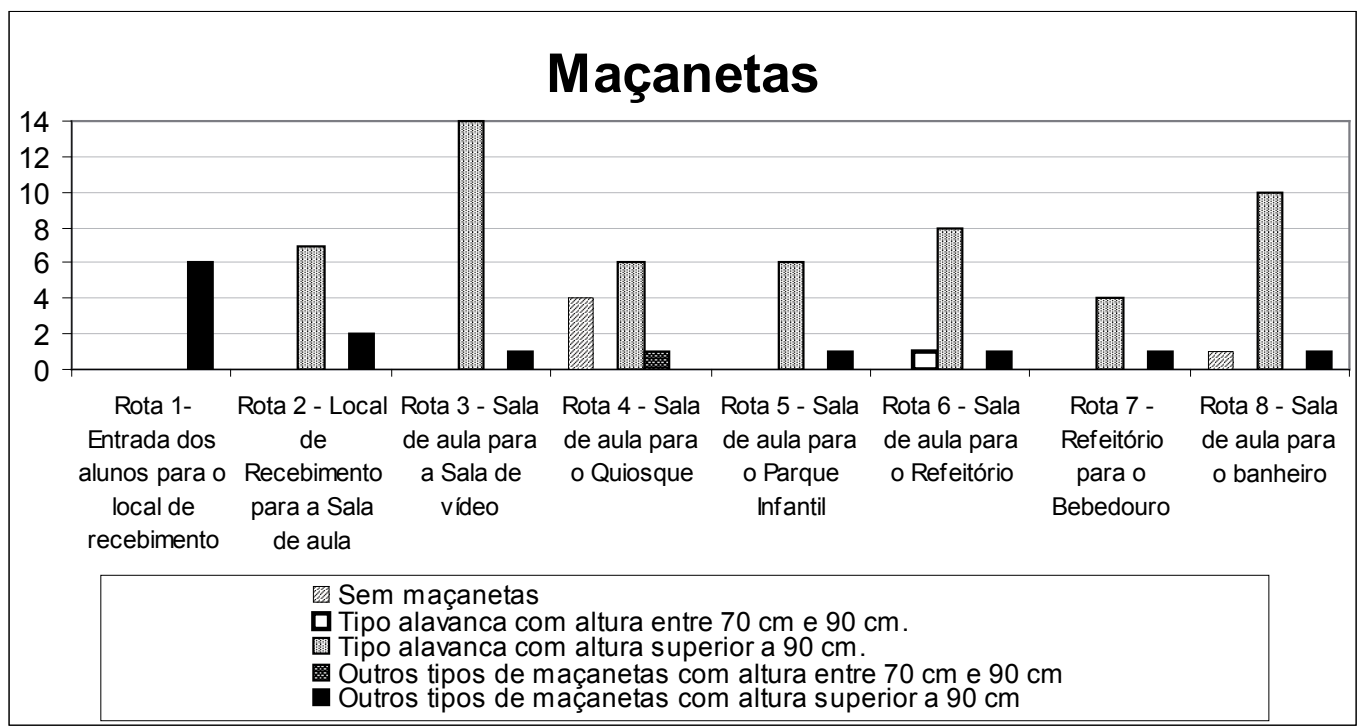

Figura 3 - Avaliação do item "tipos de maçaneta"

De acordo com a Figura 3, verifica-se que as escolas avaliadas apresentaram mais maçanetas do tipo adequado, alavanca, porém, com a altura maior que $90 \mathrm{~cm}$.

Todos os portões de entrada dos alunos não possuíam maçaneta do tipo alavanca e tinham altura maior que $90 \mathrm{~cm}$, considerada como a menos acessível. 
Apenas na Rota 6 foi observada a presença da maçaneta considerada a mais acessível em relação ao seu formato e altura.

A maçaneta do tipo alavanca é mais acessível, porque, devido ao seu formato, é mais fácil de manuseá-la, do que aos outros tipos de maçanetas. Para que um aluno da Educação Infantil e com cadeira de rodas consiga abrir uma porta, é recomendável que a maçaneta possua altura entre $70 \mathrm{~cm}$ a $90 \mathrm{~cm}$ (CARVALHO, 2008). Essa altura de maçaneta facilita igualmente o manuseio de alunos com baixa estatura.

A Figura 4 explicita os dados relativos ao item "tipo de piso" encontrado nos caminhos, calçadas, corredores ou trajetos:

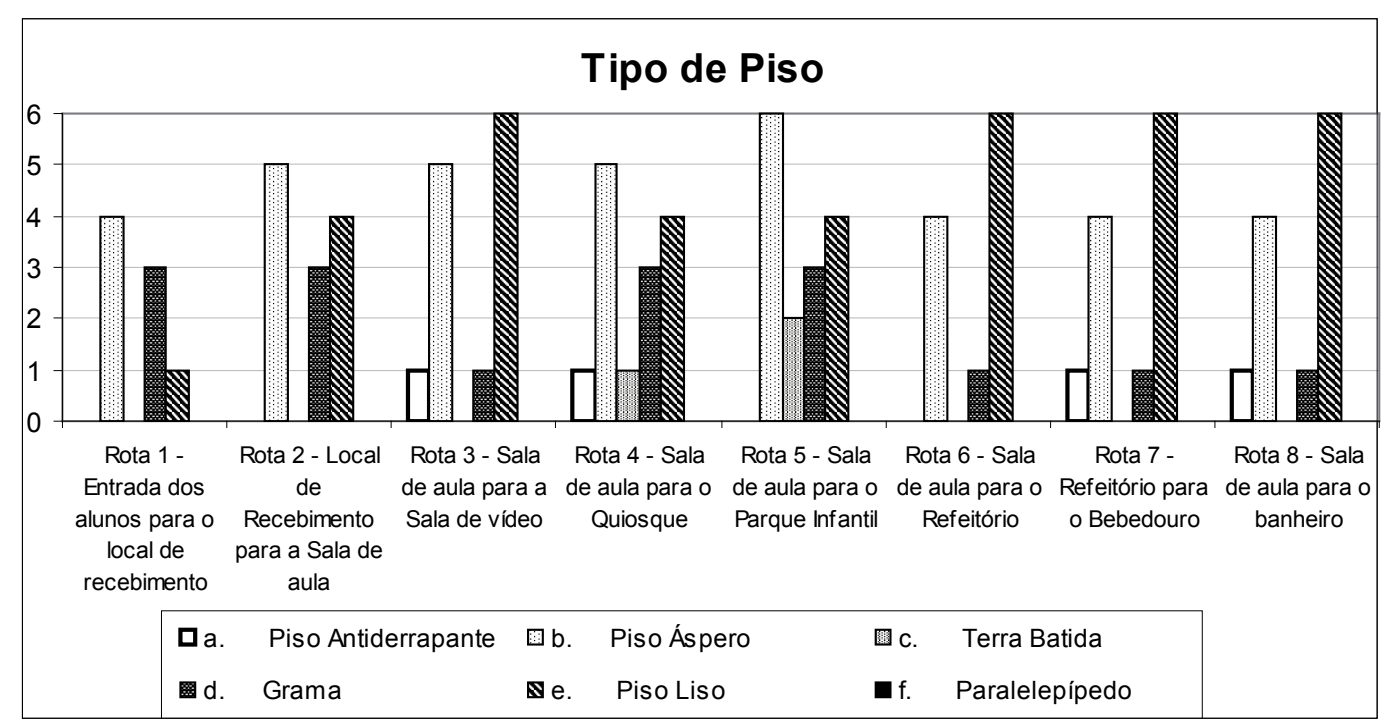

Figura 4 - Avaliação do item "tipo de piso"

O piso antiderrapante foi uma condição pouco presente nas escolas avaliadas, apenas aparecendo nas Rotas 3, 4, 7 e 8. As escolas possuíam, em sua maioria, piso áspero e liso. $O$ piso liso pode ser perigoso para os seus alunos, uma vez que pode se tornar escorregadio, principalmente quando se está molhado. A grama e a terra batida também foram encontradas em algumas escolas, de maneira a dificultar a locomoção dos alunos com deficiência física, além de ficarem escorregadias, quando molhadas.

A Figura 5 indica quais as escolas que possuem passarelas definidas nos caminhos ao ar livre: 


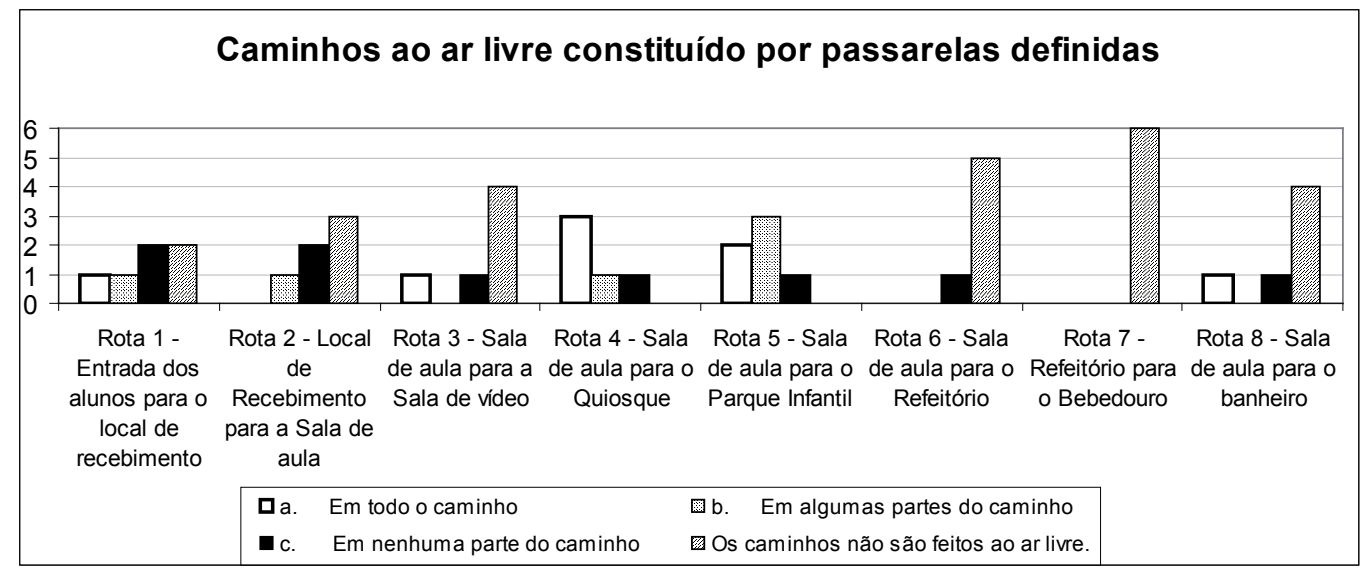

Figura 5 - Avaliação do item "presença de passarelas definidas nos caminhos ao ar livre"

De acordo com a Figura 5, nem todas as escolas apresentaram passarelas em todos os seus caminhos ao ar livre. E nas escolas em que havia, em sua maioria, as passarelas não eram em todo o seu trajeto.

As passarelas nos caminhos ao ar livre facilitam a locomoção dos alunos, principalmente daqueles que usam cadeiras de rodas e andadores, devendo estar presentes em todo o seu caminho.

A Figura 6 se refere ao item "presença de linhas-guias nos caminhos, calçadas ou corredores das escolas avaliadas":

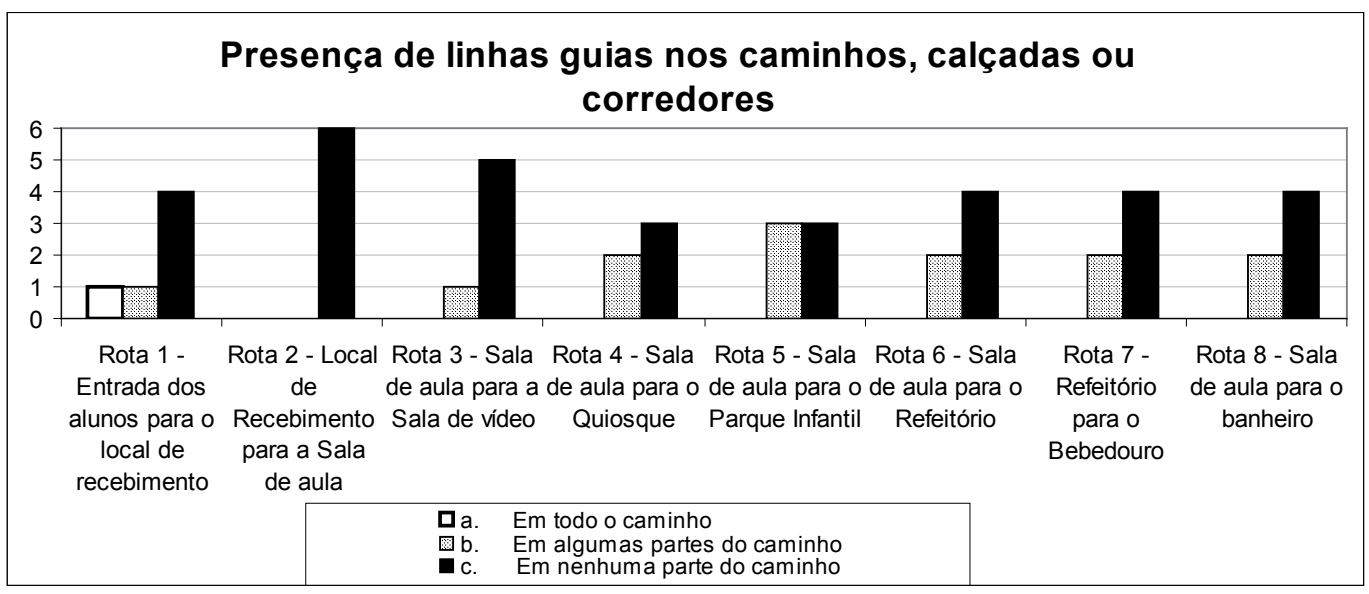

Figura 6 - Avaliação do item "presença de linhas-guias" 
Em se tratando de alunos com deficiência visual, que usam bengalas para locomover-se, é necessário definir os limites da área de circulação na escola (BRASIL, 2004). A linha-guia tem esse papel e pode ser traçada por algum elemento ou edificado.

As escolas avaliadas revelaram poucas linhas-guias em seu caminho e, na maioria das escolas, essas linhas não se constituíam em todo o caminho observado. A Rota 2 foi a que não apresentou esse item em nenhuma das escolas avaliadas.

As Figuras 7 e 8 correspondem ao item "tipos de obstáculos encontrados nas escolas":

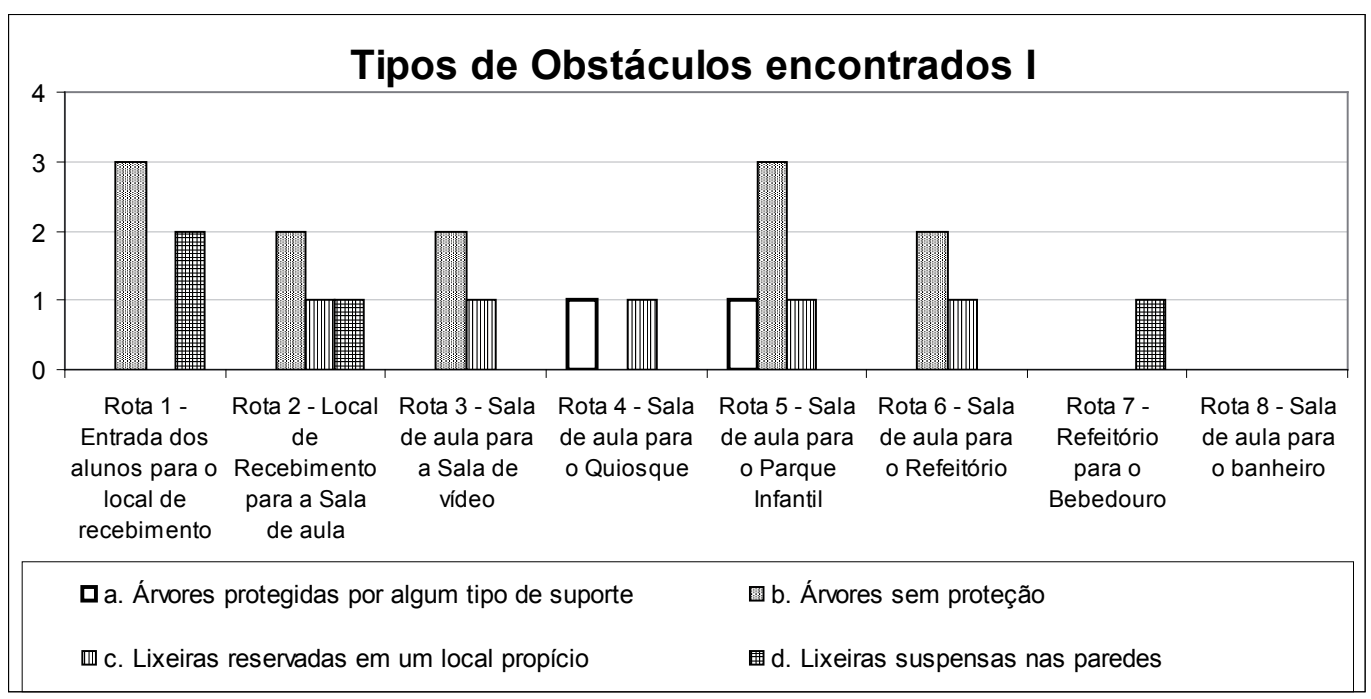

Figura 7 - Avaliação do item "presença de obstáculos" 


\section{Tipos de Obstáculos Encontrados II}

Rota 8 - Sala de aula para o banheiro

Rota 7 - Refeitório para o Bebedouro

Rota 6 - Sala de aula para o Refeitório

Rota 5 - Sala de aula para o Parque Infantil

Rota 4 - Sala de aula para o Quiosque

Rota 3 - Sala de aula para a Sala de vídeo Rota 2 - Local de Recebimento para a Sala de aula

Rota 1 - Entrada dos alunos para o local de recebimento

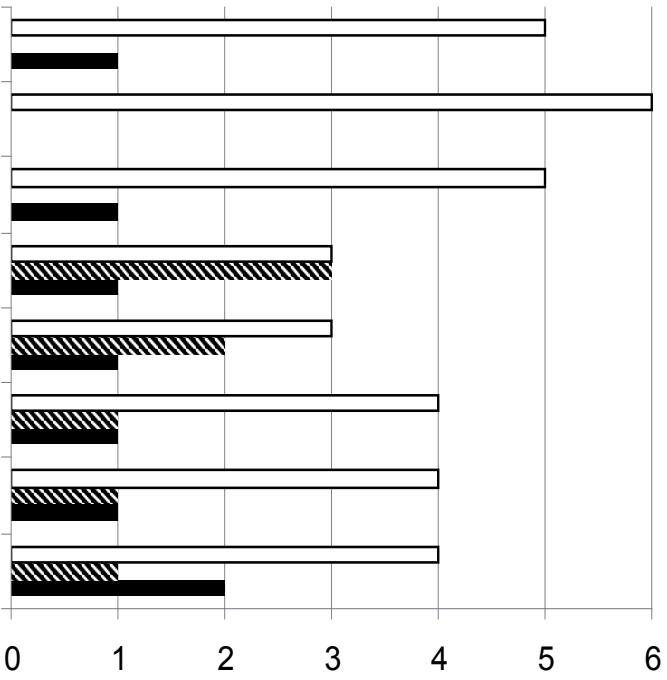

Escolas que não apresentaram osbtáculos

N Blocos de Concreto, pedaços de árvores ou outras formas de obstáculos Buracos

Figura 8 - Avaliação do item "presença de obstáculos"

Alguns elementos presentes nas escolas de Educação Infantil, como as árvores, devem ser constituídos por algum tipo de suporte de proteção, para que sejam evitadas situações de perigo, como, por exemplo, quando os alunos escalam ou se chocam com esse elemento. As lixeiras devem estar reservadas em local propício, com que os alunos não tenham contato.

Apenas as Rotas 4 e 5 mostraram suporte em árvores. As Rotas 1, 2, 3 e 6 não apresentaram esse suporte. As Rotas 7 e 8 não eram constituídas por árvores, por isso, esse item não foi avaliado nessas rotas.

Nas Rotas 2, 4, 5 e 6, foram localizadas lixeiras reservadas em um local propício. Nas Rotas 1 e 7, foram identificadas lixeiras espalhadas em locais suspensos nas paredes de alguns ambientes avaliados. Na Rota 8, não foi notada nenhuma lixeira, por isso, esse item não foi avaliado nessa rota.

As escolas com lixeiras suspensas, ao longo das rotas, não possuíam piso tátil de alerta para avisar os alunos com deficiência visual sobre a presença desse elemento, circunstância que pode acarretar uma situação de perigo para esses alunos. 
Os buracos, os blocos de concreto e os pedaços de árvores também foram considerados obstáculos que podem significar situações de perigo para os alunos, tendo sido encontrados na maioria das escolas.

A Rota 7, da Figura 8, foi a única rota que não teve nenhum tipo de obstáculo, em todas as escolas avaliadas. Nas demais rotas, algumas escolas apresentaram algum tipo de obstáculo, enquanto outras não tiveram esse item.

A Figura 9 corresponde ao item "tapetes e capachos":

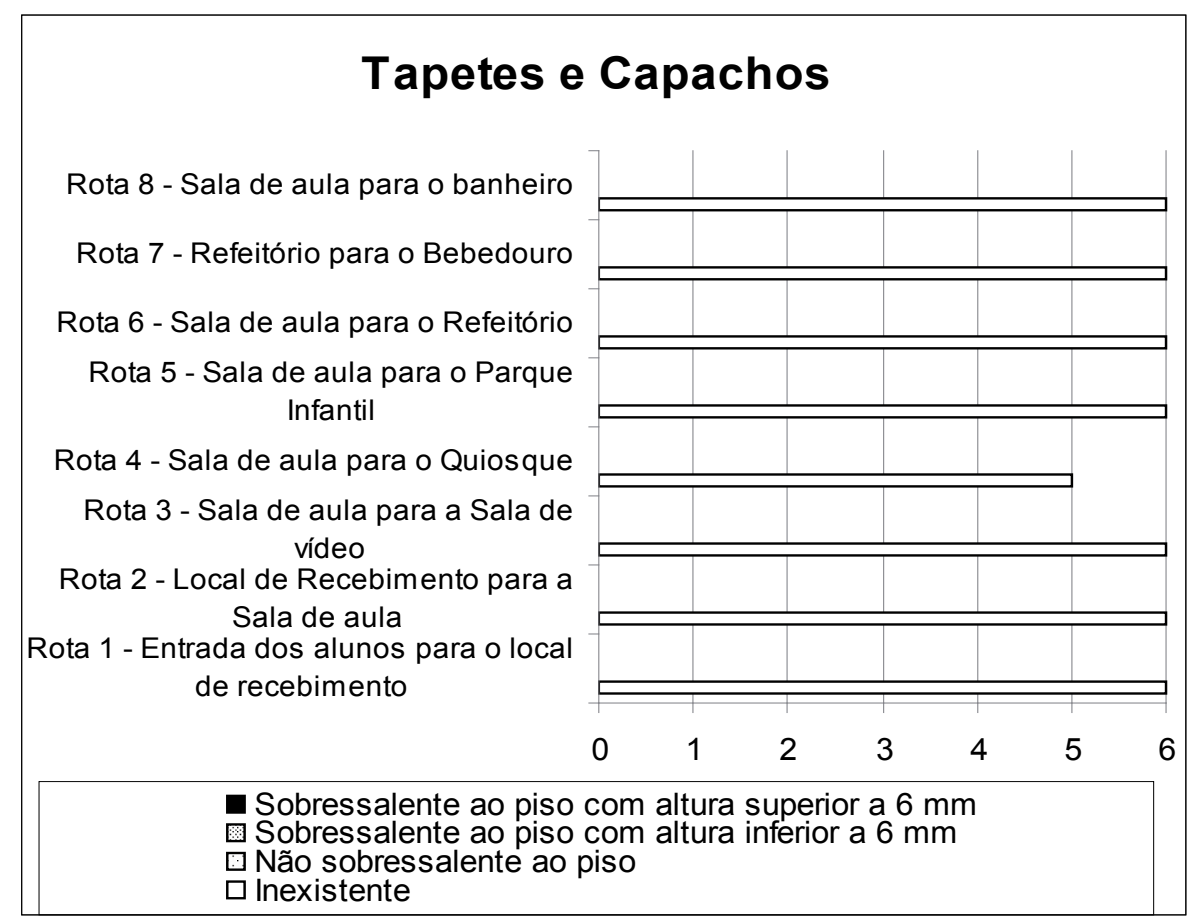

Figura 9 - Avaliação do item "tapetes e capachos"

Nenhuma das escolas avaliadas tinha tapetes ou capachos. Assim, esse item foi considerado acessível, em todas as escolas.

O item "valetas de água pluvial" está indicado na Figura 10: 


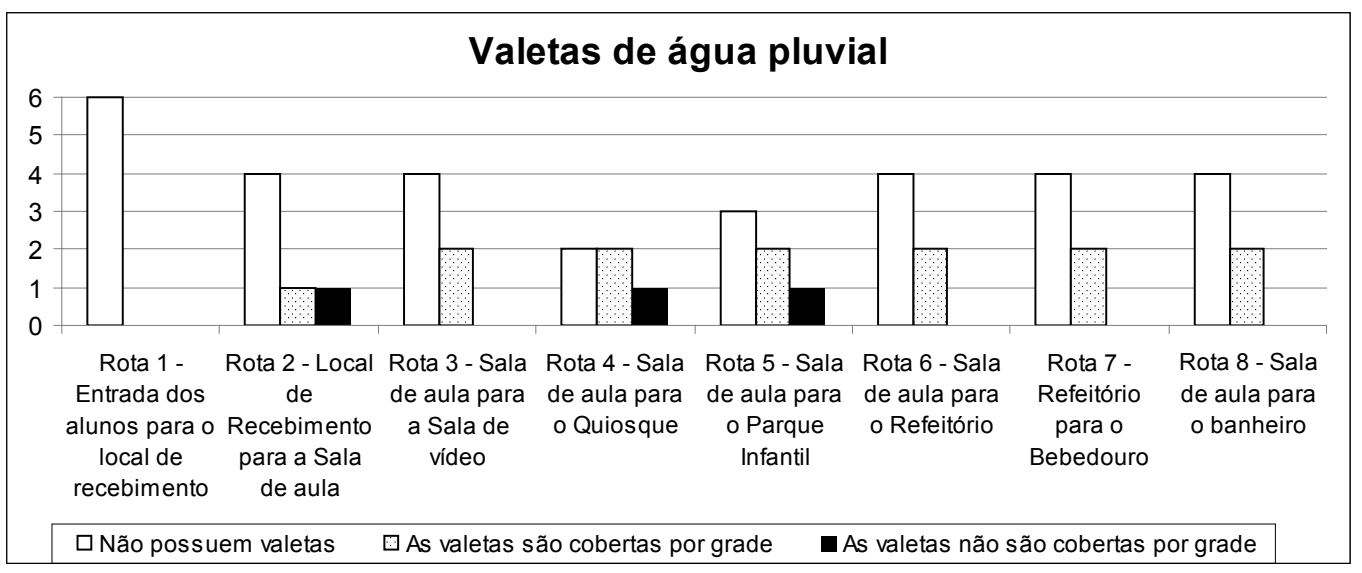

Figura 10 - Avaliação do item "presença de valetas de água pluvial"

A alternativa considerada como a menos acessível, em relação ao item valeta, foi observada nas Rotas 2, 4 e 5. Na demais rotas, ou as escolas não possuíam valetas ou essas eram cobertas por grade, tendo sido essas duas alternativas consideradas acessíveis.

A Figura 11 indica "largura dos corredores":

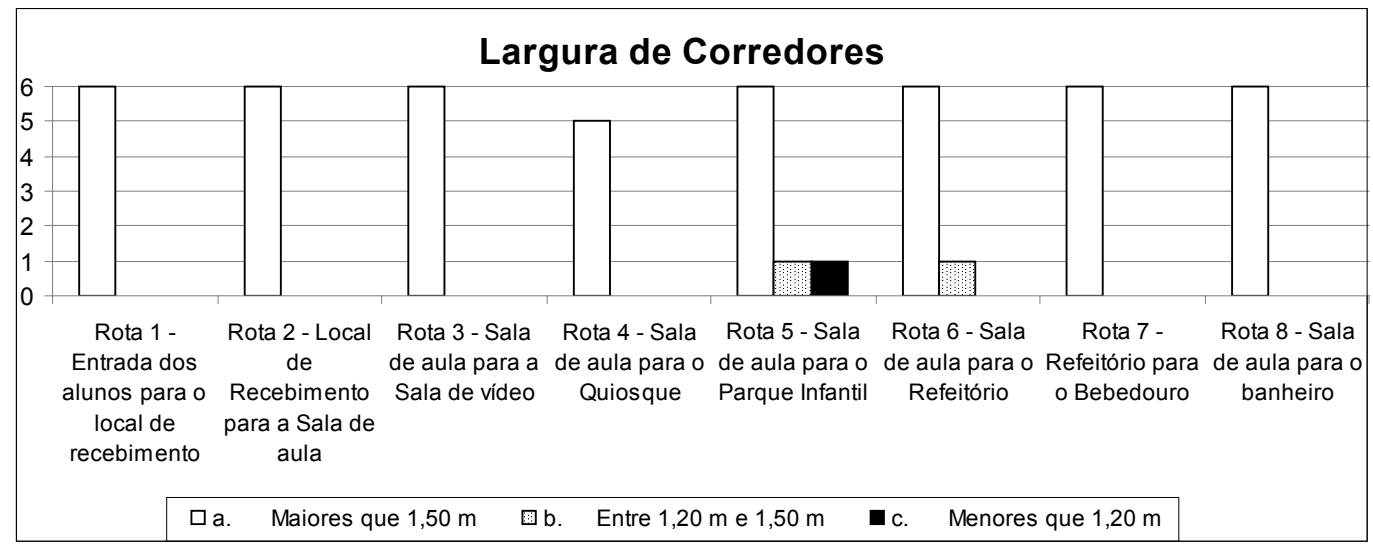

Figura 11 - Avaliação do item "largura de corredores"

As escolas avaliadas são constituídas, em sua maior parte, por corredores com ampla largura, maiores que 1,50 m, entendidos como acessíveis, porque possibilitam a circulação de dois alunos cadeirantes, ao mesmo tempo, tanto em sentido contrário quanto no mesmo sentido (AUDI, 2004).

Nas Rotas 5 e 6, observaram-se corredores com largura entre 1,20m e $1,50 \mathrm{~m}$. Os corredores com essa largura se caracterizam por boa acessibilidade, 
porém, permitem a circulação, lado a lado, apenas de um aluno com cadeira de rodas e um aluno sem nenhum aparelho de locomoção (AUDI, 2004).

A alternativa menos acessível, corredor com largura menor que 1,20m, foi percebida na Rota 5. Essa largura é considerada estreita e pode dificultar a circulação de um aluno com cadeira de rodas ou com andador (AUDI, 2004).

A Figura 12 corresponde ao item "mudança de nível":

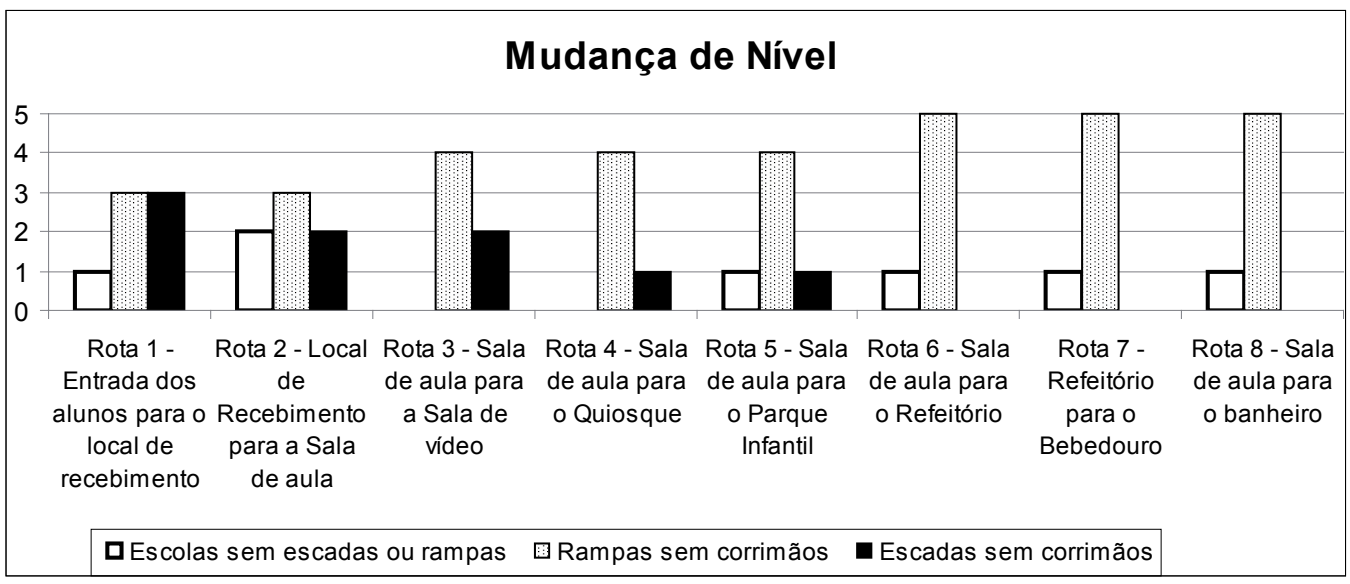

Figura 12 - Avaliação do item “mudança de nível”

Pela Figura 12, constata-se que a maioria das escolas é constituída por algum tipo de mudança de nível, em todas as rotas. Os dois tipos de mudança de nível identificados nas escolas não foram avaliados como acessíveis, porque não possuíam corrimãos. As escolas nas quais não havia mudança de nível foram as mais acessíveis.

A mudança de nível do tipo rampa foi considerada mais acessível do que a escada e foi o tipo mais encontrado nas escolas. Já o tipo escada foi observado desde a Rota 1 até a Rota 5, o que pode dificultar a circulação de um aluno com cadeira de rodas ou com andador, desde a sua entrada na escola até o seu trajeto para outros caminhos da escola, como a sala de aula, sala de vídeo, quiosque e parque infantil. dos alunos":

A Figura 13 corresponde ao item "tipo de piso do local de recebimento 


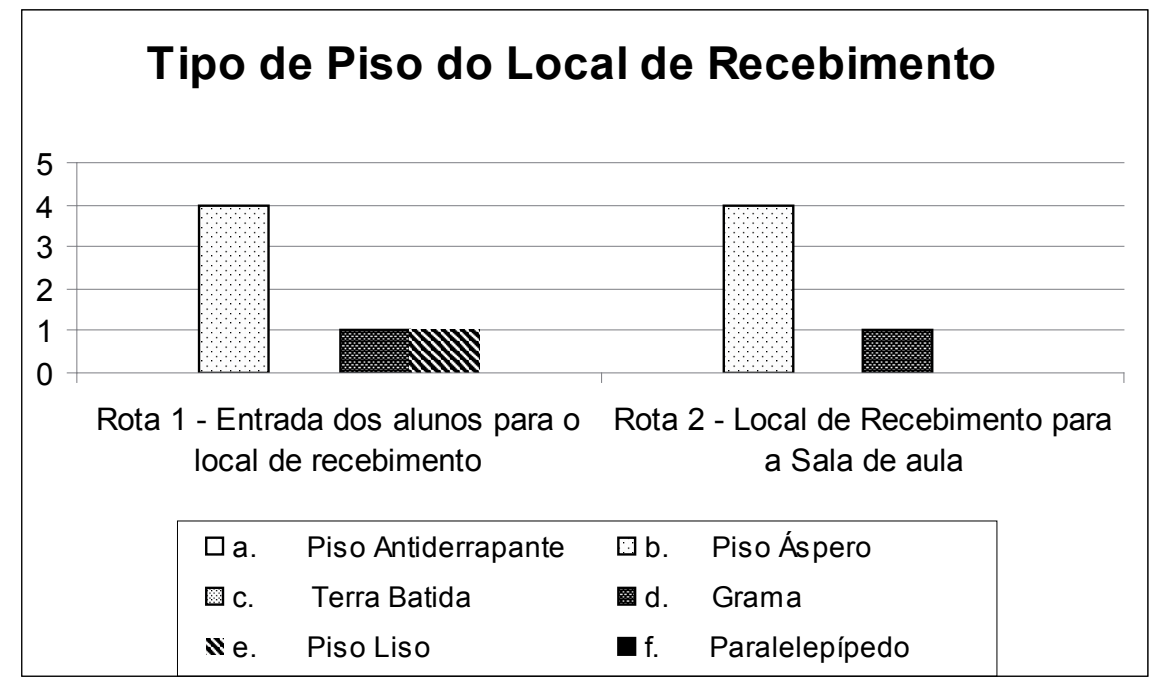

Figura 13 - Avaliação do item "tipo de piso do local de recebimento dos alunos"

O piso antiderrapante, que é o mais acessível, não foi encontrado em nenhuma parte das escolas avaliadas nas Rotas 1 e 2.

Na Rota 1, verificou-se a presença de piso áspero, grama e piso liso, ao passo que a Rota 2 era constituída por piso áspero e grama.

O piso áspero é mais acessível do que o piso liso e a grama, porém, todos esses pisos não são ideais e podem ser escorregadios para os alunos circularem, sobretudo quando molhados.

O tipo de piso das salas está indicado na Figura 14:

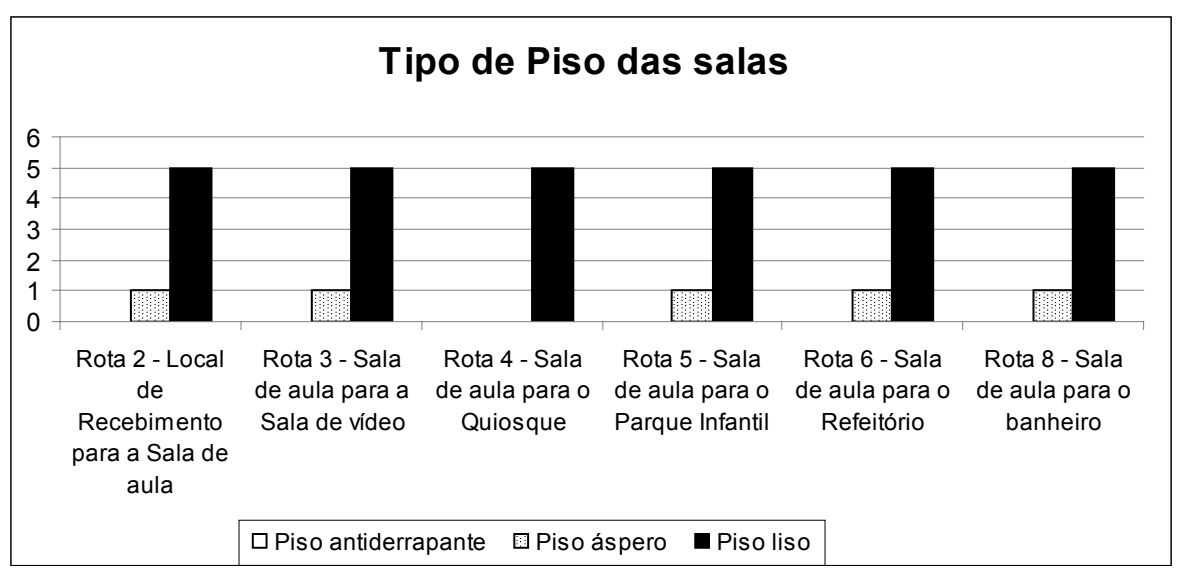

Figura 14 - Avaliação do item "tipo de piso das salas" 
Essa figura se refere aos tipos de piso das salas de aula e de vídeo. O piso liso, classificado como o menos acessível, foi o mais observado nas escolas, nesses espaços.

O tipo de piso liso também foi encontrado, tanto no refeitório como no banheiro de todas as escolas avaliadas. O banheiro é um lugar em que, ao ser usado, os alunos podem derramar água ao redor da pia e escorregarem.

Na Figura 15, é indicado o tipo de piso encontrado no bebedouro:

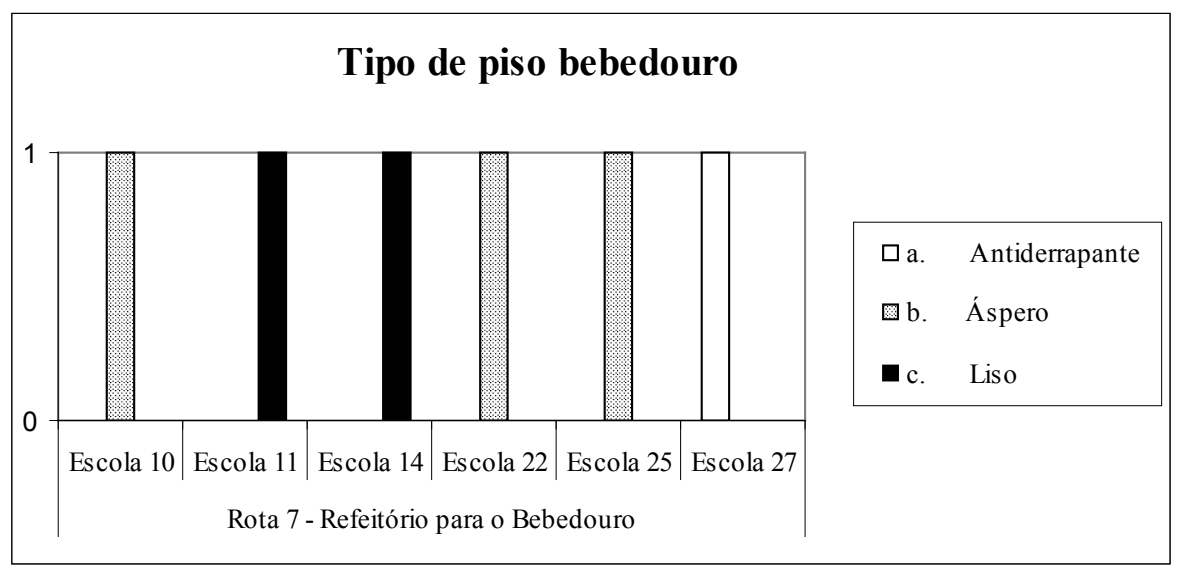

Figura 15- Avaliação do item "tipo de piso do bebedouro"

O piso antiderrapante no bebedouro foi apenas encontrado na Escola 27. É importante que o entorno do bebedouro seja constituído por piso antiderrapante, para evitar que os alunos escorreguem e batam nesse elemento arquitetônico, pois, quando é utilizado, a área ao seu redor fica geralmente molhada.

Em relação ao item "tipo de bebedouro", em todas as escolas avaliadas, foi encontrado o tipo de bebedouro menos acessível, que possui torneira com altura única, sem base recuada e sem barras de apoio. É importante que o bebedouro tenha dupla altura de torneira, de modo a facilitar a sua utilização pelos alunos com baixa estatura; a base recuada facilita a aproximação dos alunos cadeirantes e as barras de apoio servem para os alunos se segurarem (AUDI, 2004).

Para os itens quadra de esporte, tanque de areia, campo de futebol, piscina e banheiro adaptado não foram elaborados gráficos, visto que não foi encontrada nenhuma das características sugeridas nesses elementos, nas escolas avaliadas, ou seja, essas escolas não possuem lugares reservados para cadeirantes, na quadra de esporte e campo de futebol, nem banheiro adaptado, dentre outras sugestões do protocolo.

Deve ser ressaltado que o protocolo elaborado possibilita que os profissionais do atendimento educacional especializado cumpram com algumas das suas funções de identificar, elaborar e organizar recursos pedagógicos e de 
acessibilidade que eliminem as barreiras para a plena participação dos alunos, considerando suas necessidades específicas (BRASIL, 2007).

\section{CONClusÃo}

Com a aplicação do protocolo, foi possível comparar e distinguir as condições de acessibilidade de cada um de seus itens, entre as seis escolas avaliadas. Com esse instrumento, pôde-se identificar quais escolas que fizeram parte da pesquisa parecem ter incorporado algumas características de acessibilidade física, em alguns itens, como: a) a largura e o desnível da soleira do portão de entrada dos alunos e das portas; b) a não presença de tapetes e capachos; $c$ ) as grades nas valetas de água pluvial; d) a largura dos corredores. Porém, alguns itens ainda necessitam de melhores projeções, pois foi percebida ausência: a) do piso antiderrapante; $b$ ) de passarelas dos caminhos ao ar livre; c) de linhas-guias; d) de suportes de proteção nas árvores; e) do piso tátil de alerta, nas lixeiras suspensas; f) dos corrimãos com dupla altura, nas escadas e nas rampas; g) de lugares reservados para cadeirantes, nas quadras de esportes e campos de futebol; h) de plataforma para a transferência de alunos cadeirantes e encosto, nos tanques de areia; i) de banco de transferência, na piscina; j) de bebedouro com dupla altura de torneira, base recuada e barras de apoio junto ao equipamento, fixadas na parede; 1) de banheiro adaptado.

Além disso, essas escolas também precisam pensar em algumas formas de resolver as situações de perigo criadas pelos buracos, blocos de concreto e pedaços de árvores existentes.

\section{REFERÊNCIAS}

ALPINO, A. M. S. O aluno com paralisia cerebral no Ensino Regular: ator ou expectador do processo educacional? 2003. 147 f. Dissertação (Mestrado em Educação Especial) - Centro de Educação e Ciências Humanas, Universidade Federal de São Carlos, São Carlos, 2003.

AUDI, E. M. M.; MANZINI, E. J. Protocolo para avaliação de acessibilidade em escolas do Ensino Fundamental: um guia para gestores e educadores. Marília: ABPEE, 2006.

AUDI, E. M. M. Protocolo para avaliação de acessibilidade física em escolas de Ensino Fundamental. 2004. 228 f. Dissertação (Mestrado em Educação) - Faculdade de Filosofia e Ciências, Universidade Estadual Paulista, Marília, 2004.

BRASIL. Ministério da Educação. Secretaria de Educação Especial. Política Nacional de Educação Especial na Perspectiva da Educação Inclusiva. Documento elaborado pelo Grupo de Trabalho nomeado pela Portaria Ministerial $\mathrm{n}^{0}$ 555, de 5 de junho de 2007, prorrogada pela Portaria no 948, de 09 de outubro de 2007. Brasília, DF. MEC/SEESP, 2007.

. Associação Brasileira de Normas Técnicas. NBR 9050: Acessibilidade a edificações, mobiliário, espaços e equipamentos urbanos. Rio de Janeiro: ABNT, 2004.

CALADO, G. C. Acessibilidade no ambiente escolar: reflexões com base no estudo de duas escolas municipais de Natal-RN. 2006. 166 f. Dissertação (Mestrado em Arquitetura e Urbanismo) - Centro de Tecnologia, Universidade Federal do Rio Grande do Norte, Natal, 2006. 
CARVALHO, T. C. P. Arquitetura escolar inclusiva: construindo espaços para educação infantil. 2008. 344 f. Tese (Doutorado em Arquitetura e Urbanismo) - Escola de Engenharia de São Carlos, Universidade de São Paulo, São Carlos, 2008.

CASTRO, F. F. M. Relação espaço-aprendizado: uma análise do ambiente pré-escolar. 2000. 169 f. Dissertação (Mestrado em Arquitetura e Urbanismo) - Faculdade de Arquitetura e Urbanismo, Universidade de São Paulo, São Paulo, 2000.

CORRÊA, P. M. Elaboração de um protocolo para avaliação de acessibilidade em escolas da Educação Infantil. 2010. 174 f. Dissertação (Mestrado em Educação) - Faculdade de Filosofia e Ciências, Universidade Estadual Paulista, Marília, 2010.

DISCHINGER, M. et al. (Org.). Desenho Universal nas escolas: acessibilidade na rede municipal de ensino de Florianópolis. Florianópolis: Prelo, 2004.

ELALI, G. A. Ambientes para Educação Infantil: um quebra-cabeça? Contribuição Metodológica na avaliação Pós-ocupação de edificações e na elaboração de diretrizes para projetos arquitetônicos na área. 2 v. 2002. 305 f. Tese (Doutorado em Estruturas Ambientais e Urbanas) - Faculdade de Arquitetura e Urbanismo, Universidade de São Paulo, São Paulo, 2002.

LAUAND, G. B. A. Acessibilidade e formação continuada na inserção escolar de crianças com deficiências físicas e múltiplas. 2000. 121 f. Dissertação (Mestrado em Educação Especial) - Centro de Educação e Ciências Humanas, Universidade Federal de São Carlos, São Carlos, 2000.

Recebido em: 01/06/2011

Reformulado em: 26/11/2011

Aprovado em: 30/03/2012 